\title{
Natural Course of Cutaneous Warts Among Primary Schoolchildren: A Prospective Cohort Study
}

Sjoerd C. Bruggink, MD

Just A. H. Eekhof, MD, PbD

Paulette F. Egberts, MD

Sopbie C. E. van Blijswijk, MSc

Willem J. J. Assendelft, MD, PbD

Jacobijn Gussekloo, MD, PhD

Department of Public Health and Primary Care, Leiden University Medical Center, Leiden, The Netherlands
Conflicts of interest: authors report none.

\section{CORRESPONDING AUTHOR}

Sjoerd C. Bruggink, MD

Postal Box 9600

2300 RC Leiden

The Netherlands

s.c.bruggink@lumc.nl

\begin{abstract}
PURPOSE Because cutaneous warts resolve spontaneously and available treatments often fail, family physicians and patients may consider a wait-and-see policy. We examined the natural course of cutaneous warts and treatment decisions in a prospective observational cohort of primary schoolchildren.
\end{abstract}

METHODS We inspected the hands and feet of children aged 4 to 12 years from 3 Dutch primary schools for the presence of warts at baseline and after a mean follow-up of 15 months. Parental questionnaires at follow-up provided information on inconvenience caused by warts and any treatments used.

RESULTS Of the 1,134 eligible children, 1,099 (97\%) participated, of whom 366 (33\%) had cutaneous warts at baseline. Among these children with warts, loss to follow-up was $9 \%$ and the response rate to the parental questionnaires was $83 \%$. The complete resolution rate was 52 per 100 person-years at risk (95\% $\mathrm{Cl}, 44-60$ ). Younger age (hazard ratio $=1.1$ per year decrease; $95 \% \mathrm{Cl}, 1.0-1.2$ ) and non-Caucasian skin type (hazard ratio $=2.0 ; 95 \% \mathrm{Cl}, 1.3-2.9$ ) increased the likelihood of resolution. During follow-up, $38 \%$ of children with warts at baseline treated their warts: $18 \%$ used over-the-counter treatment only, $15 \%$ used a family physician-provided treatment only, and $5 \%$ used both. Children were more likely to initiate treatment if the warts measured at least $1 \mathrm{~cm}$ in diameter (odds ratio $=3.2 ; 95 \% \mathrm{Cl}, 1.9-5.3)$ and especially if parents reported that the warts caused inconvenience (odds ratio $=38 ; 95 \% \mathrm{Cl}, 16-90$ ).

CONCLUSIONS One-half of primary schoolchildren with warts will be free of warts within 1 year. Young age and non-Caucasian skin type enhance resolution. Children with large or inconvenient warts are more likely to start treatment. These findings will be useful in the process of shared decision making with parents and children.

Ann Fam Med 2013;437-441. doi:10.1370/afm.1508

\section{INTRODUCTION}

utaneous warts are caused by the human papillomavirus. Small defects of the skin are sufficient to allow the virus to infect the basal layer of the skin, which may lead to benign hyperkeratotic papillomas. ${ }^{1}$ Warts are very common in the general population, especially among children. The prevalence of warts among primary schoolchildren is reported to be $22 \%$ to $33 \%,{ }^{2,3}$ while the annual prevalence based on consultations in general practice is about $6 \%{ }^{4,5}$ This difference in rates indicates that only a proportion of children seek medical advice or treatment for warts.

Liquid nitrogen cryotherapy and application of concentrated (30\%$50 \%)$ salicylic acid are treatments most frequently used for warts by family physicians. ${ }^{6}$ Less potent over-the-counter (OTC) cryotherapy or salicylic acid (usually $17 \%$ ) treatments are offered in pharmacies without a prescription. ${ }^{7}$ Because warts resolve spontaneously and available treatments often fail, especially in the case of plantar warts, ${ }^{8-10}$ a wait-and-see policy may be considered in treatment decisions. ${ }^{11}$ Studies on the natural course of warts are scarce and outdated, however. ${ }^{12-14}$ 
We therefore undertook a study examining the natural course of cutaneous warts and treatment decisions in a prospective observational cohort of primary schoolchildren.

\section{METHODS}

\section{Study Cohort and Procedures}

At baseline, we included all children in grades 1 through 7 from 3 primary schools in and around the city of Leiden, the Netherlands. A trained medical student examined the hands and feet of all children for the presence of warts. The details of this baseline examination have been previously reported. ${ }^{3}$ One year later, another trained medical student examined the hands and feet of all children who had had warts at baseline (now in grades 2-8), again for the presence of warts. Mean follow-up was 15 months, with a range of 11 to 18 months because of practical reasons and taking into account school vacations. Parents were asked to give informed consent before both examinations. Apart from this requirement, children were free to decline participation during examinations. The study was approved by the Medical Ethics Committee of the Leiden University Medical Center, as well as by the boards of the participating schools.

\section{Presence of Warts}

At baseline and follow-up, the type and number of warts were recorded on standard forms with schematic representation of the hands and feet. A distinction was made between plantar warts (located on the sole of the feet) and common warts (located on the hands or the dorsal aspect of the feet). Complete resolution was defined as a complete absence of warts at the follow-up examination. A wart was considered completely resolved when it was no longer visible (skin color and skin lines were reestablished) and could no longer be palpated by hand. More than 5\% of both the baseline and the follow-up examinations were supervised by experienced family physicians, with no discordance regarding wart diagnosis or resolution.

\section{Factors Influencing Resolution}

During the baseline examination, clinicians recorded the children's demographic and wart factors. The demographic factors were age (split on the median: 4-7 years vs $8-12$ years), sex (female vs male), and skin type (coded according to Fitzpatrick ${ }^{15}$ as Caucasian vs non-Caucasian). The wart factors assessed were type (plantar vs common), number (single vs multiple), and size $(<1 \mathrm{~cm}$ vs $\geq 1 \mathrm{~cm})$.

\section{Treatment Decisions}

Before the follow-up examination, parents were asked to complete a questionnaire about the inconvenience caused by warts present at any time during the followup period and which treatments, if any, were initiated for these warts. The following factors were recorded. Inconvenience of warts was characterized according to type (pain, irritation, unsightly appearance, opinion of others) and amount (on a scale from 0 [no inconvenience] to 4 [considerable inconvenience]). Initiated treatment was classified according to family physician involvement (OTC vs family physician provided) and specific type (cryotherapy vs salicylic acid application vs other).

\section{Statistical Analyses}

We calculated resolution rates with 95\% CIs, dividing the number of children with complete resolution by the sum of the person-time of children at risk (personyears at risk). To calculate person-time at risk, we considered the date of resolution to be halfway through the follow-up period. In addition, we calculated resolution rates for plantar and common warts individually, as well as the resolution rate when only baseline warts were considered, that is, new warts that developed during the follow-up period were disregarded.

We used Cox proportional hazards models to identify factors enhancing resolution. Univariate analysis was performed for demographic, wart, and treatment factors to estimate hazards ratios (HRs) with 95\% CIs. We performed multivariate analysis with all factors to assess which relations were independent. In subgroup analysis, HRs were calculated for children with plantar warts separately. In addition, we used a logistic regression model to explore factors related to the decision to treat warts. Odds ratios (ORs) with 95\% Cls were calculated for demographic, wart, and inconvenience factors.

\section{RESULTS}

\section{Study Cohort}

Of 1,134 eligible children at baseline, 1,099 (97\%) participated: 23 children (2\%) were absent from school at the time of baseline examinations, and for 12 children $(1 \%)$, parental or child consent was not given.

At baseline, 366 children (33\%) had warts on examination. Overall, 33 (9\%) of this group were lost to follow-up: 24 children (7\%) left school, and for 9 children $(2 \%)$, parental or child consent was not given for the follow-up examination. At baseline, the median age of the 333 children included in the follow-up was 8 years (interquartile range $=5-10$ years), $49 \%$ were male, and $15 \%$ had a non-Caucasian skin type, originating from Morocco, Turkey, China, the Netherlands Antilles, or Surinam (Table 1). In total, $42 \%$ of the children 
had common warts and $70 \%$ had plantar warts; $43 \%$ had multiple warts, and $37 \%$ had a wart measuring at least $1 \mathrm{~cm}$ in diameter.

\section{Resolution of Warts}

The complete resolution rate was 52 per 100 person-years ( $95 \% \mathrm{CI}$, 44-60). When newly developed warts were excluded, the resolution rate of baseline warts was even higher: 90 per 100 personyears (95\% CI, 79-100). Rates were similar for both common warts and plantar warts individually.

\section{Factors Influencing \\ Resolution}

The likelihood that warts would resolve was higher for younger children $(\mathrm{HR}=1.1 \mathrm{per}$ year decrease; $95 \% \mathrm{CI}$, 1.0-1.2, $P=.003)$ and non-Caucasian skin type $(\mathrm{HR}=2.0 ; 95 \% \mathrm{CI}, 1.3$ $2.9, P=.001)$, whereas the type, number, and size of the warts did not predict resolution (Table 2). Multivariate analysis showed almost the same results, with the only difference being that in this model, the likelihood of resolution increased slightly with the number of warts $(\mathrm{HR}=1.1$ per each additional wart; $95 \% \mathrm{CI}$, 1.0-1.2, $P=.04)$. Subgroup analysis of children with plantar warts and the analysis considering only warts present at baseline yielded results similar to those of the primary analysis considering all warts, including those that developed during follow-up.

\section{Treatment Decisions}

Of 333 parental questionnaires distributed, 276 (83\%) were returned. Within this group, parents of 73 children (26\%) reported that the warts caused inconvenience, and parents of 106 children (38\%) reported that the warts were treated with OTC or family physician-provided treatments during follow-up (Table 3). Two children were referred to a dermatologist. Initiated treatments were similar for common warts
Table 1. Baseline Characteristics of the Children With Warts Included in the Follow-up $(n=333)$

\begin{tabular}{|c|c|c|c|}
\hline Characteristic & Value & Characteristic & Value \\
\hline Age, median, y & $8(4-12)$ & Type of warts, No. (\%) & \\
\hline Sex, No. (\%) & & Common only & $100(30)$ \\
\hline Male & $162(49)$ & Plantar only & $192(58)$ \\
\hline Female & $171(51)$ & Both & $41(12)$ \\
\hline Skin type, No. (\%) & & Number of warts, No. (\%) & \\
\hline Caucasian & $284(85)$ & 1 wart & $191(57)$ \\
\hline Non-Caucasian & $49(15)$ & 2 warts & $63(19)$ \\
\hline School, No. (\%) & & 3-5 warts & $52(16)$ \\
\hline School A, 28 classes & $219(66)$ & $\geq 6$ warts & $27(8)$ \\
\hline School C, 8 classes & $27(8)$ & Presence of warts $\geq 1 \mathrm{~cm}$, No. (\%) & \\
\hline \multirow[t]{2}{*}{ School D, 12 classes } & $87(26)$ & No & $209(63)$ \\
\hline & & Yes & 124 (37) \\
\hline
\end{tabular}

Table 2. Univariate Associations of Demographic and Wart Factors at Baseline With the Resolution of All Warts

\begin{tabular}{|c|c|c|c|c|}
\hline $\begin{array}{l}\text { Potential Risk } \\
\text { Factor }\end{array}$ & $\begin{array}{l}\text { No. of Casesl } \\
\text { Person-Years }\end{array}$ & $\begin{array}{c}\text { Resolution } \\
\text { Rate per } 100 \\
\text { Person-Years }\end{array}$ & HR $(95 \% \mathrm{Cl})^{\mathrm{a}}$ & $\begin{array}{c}P \\
\text { Value }\end{array}$ \\
\hline \multicolumn{5}{|l|}{ Demographic factors } \\
\hline \multicolumn{5}{|l|}{ Age in years } \\
\hline $8-12$ & $80 / 176$ & 45 & 1.0 (ref) & \\
\hline $4-7$ & $82 / 137$ & 60 & $1.5(1.1-2.0)$ & .02 \\
\hline Age, per year decrease & - & - & $1.12(1.04-1.20)$ & .003 \\
\hline \multicolumn{5}{|l|}{ Sex } \\
\hline Female & $76 / 164$ & 46 & 1.0 (ref) & \\
\hline Male & $86 / 149$ & 58 & $1.3(0.9-1.7)$ & .13 \\
\hline \multicolumn{5}{|l|}{ Skin type } \\
\hline Caucasian & $129 / 274$ & 47 & 1.0 (ref) & \\
\hline Non-Caucasian & $33 / 39$ & 85 & $2.0(1.3-2.9)$ & .001 \\
\hline \multicolumn{5}{|l|}{ Wart factors } \\
\hline \multicolumn{5}{|l|}{ Type } \\
\hline Common only & $50 / 94$ & 53 & 1.0 (ref) & \\
\hline Plantar only & $96 / 181$ & 53 & $1.0(0.7-1.4)$ & .88 \\
\hline Both & $16 / 38$ & 42 & $0.7(0.4-1.2)$ & .19 \\
\hline \multicolumn{5}{|l|}{ Number } \\
\hline Single & $90 / 184$ & 49 & 1.0 (ref) & \\
\hline Multiple & $72 / 129$ & 56 & $1.1(0.8-1.4)$ & .71 \\
\hline $\begin{array}{l}\text { Number, per additional } \\
\text { wart }\end{array}$ & - & - & $1.03(0.96-1.10)$ & .43 \\
\hline \multicolumn{5}{|l|}{ Size } \\
\hline$\geq 1 \mathrm{~cm}$ & $55 / 117$ & 47 & 1.0 (ref) & \\
\hline$<1 \mathrm{~cm}$ & $106 / 194$ & 55 & $1.2(0.9-1.6)$ & .29 \\
\hline
\end{tabular}


The decision to initiate treatment of warts during follow-up (OTC and family physician treatment combined) was not related to age, sex, skin type, or wart type at baseline, but was related to the size of the wart at baseline (OR for $\geq 1-\mathrm{cm}$ vs $<1-\mathrm{cm}$ diameter $=3.2$; 95\% CI, 1.9-5.3, $P<.001)$, persistence (OR not resolved vs resolved warts at follow-up $=2.0 ; 95 \% \mathrm{CI}, 1.2-3.3$, $P=.01)$, and the reported inconvenience caused by warts (OR inconvenience vs no inconvenience $=38$; 95\% CI, 16-90, $P<.001$ ) (Table 4). Multivariate analysis with all of the above factors showed comparable results.

\section{DISCUSSION}

One-half of primary schoolchildren found to have warts at a given time will be free of warts 1 year later. Among young children and children with non-Caucasian skin type, resolution rates are even higher. During follow-up, 38\% of children and their parents decided to treat the warts, a decision that was more likely when warts were bigger and bothersome.

\section{Comparison With Other Studies}

The most cited study on the natural course of cutaneous warts reported that 113 of 168 children (67\%) were free of warts after 2 years. ${ }^{12}$ None were treated during

\begin{tabular}{|c|c|}
\hline Inconvenience and Treatment & No. (\%) \\
\hline Any inconvenience caused by warts & $73(26)$ \\
\hline Pain & $23(8)$ \\
\hline Irritation & $28(10)$ \\
\hline Unsightly appearance & $38(14)$ \\
\hline Bothered by opinion of others & $10(4)$ \\
\hline Initiated treatment & $106(38)$ \\
\hline OTC treatment only & $49(18)$ \\
\hline Family physician treatment only & $41(15)$ \\
\hline Both & $16(5)$ \\
\hline \multicolumn{2}{|l|}{ Specific OTC treatments ${ }^{b}$} \\
\hline Dimethylether/propane cryotherapy & $28(10)$ \\
\hline Low-dose (17\%) salicylic acid & $37(13)$ \\
\hline Duct tape & $2(1)$ \\
\hline Other & $12(4)$ \\
\hline \multicolumn{2}{|l|}{ Family physician treatments ${ }^{c}$} \\
\hline Liquid nitrogen cryotherapy & $49(18)$ \\
\hline High-dose (40\%-50\%) salicylic acid & $14(5)$ \\
\hline Other & $3(1)$ \\
\hline \multicolumn{2}{|l|}{ OTC = over the counter. } \\
\hline \multicolumn{2}{|c|}{$\begin{array}{l}\text { a Response to parental questionnaires was } 276 \text { of } 333(83 \%) \text {. } \\
\text { b Initiated treatments were comparable for common warts and plantar warts. } \\
\text { ' More than } 1 \text { option possible: } 23 \text { children reported more than } 1 \text { type of incon- } \\
\text { venience, } 13 \text { children used more than } 1 \text { OTC treatment, and } 9 \text { children used } \\
\text { more than } 1 \text { family physician treatment. }\end{array}$} \\
\hline
\end{tabular}

follow-up; however, that study was conducted in 1963 in an institutionalized mentally disabled population. Another study conducted in 1959 finding a complete resolution after 1 year in 77 of 136 patients (57\%) included only hand warts in Dutch primary schoolchildren, ${ }^{13}$ and a more recent cohort of British children aged 11 years showed a 5 -year resolution rate of 337 of 364 cases (93\%) but did not provide data on a shorter follow-up..$^{14}$ Despite all the methodologic limitations, the natural course in these latter studies is roughly in line with that in our study.

Although the full complexity of the relationship between the persistence of warts and immunologic responses is not yet entirely elucidated ${ }_{1}^{16}$ the current study shows that age and ethnic factors play a role in the resolution of warts. In agreement with others, we found that the location and size of warts do not seem to influence this outcome. ${ }^{12,13}$ Associations with the number of warts are not consistent in other studies, ${ }^{10,12,13}$ and we could not provide clear evidence on this issue either.

\section{Strengths and Limitations}

This study with a participation rate of $97 \%$ shows the natural course of warts in a current primary school population in western Europe. Although the data did not allow us to draw conclusions on time to resolution

Table 4. Univariate Associations of Demographic and Wart Factors at Baseline and Inconvenience With the Decision to Treat Warts $(n=276)$

\begin{tabular}{|c|c|c|}
\hline Factor & OR $(95 \% \mathrm{Cl})^{a}$ & $P$ Value \\
\hline \multicolumn{3}{|l|}{ Demographic factors } \\
\hline Age (per year increase in age) & $1.1(0.9-1.2)$ & .33 \\
\hline Female sex & $1.3(0.8-2.1)$ & .28 \\
\hline Caucasian skin type & $1.6(0.8-3.2)$ & .24 \\
\hline \multicolumn{3}{|l|}{ Wart factors } \\
\hline Plantar location & $1.1(0.7-2.0)$ & .66 \\
\hline Number (per additional wart) & $1.1(1.0-1.2)$ & .08 \\
\hline Size $\geq 1 \mathrm{~cm}$ & $3.2(1.9-5.3)$ & $<.001$ \\
\hline Warts not resolved at follow-up ${ }^{b}$ & $2.0(1.2-3.3)$ & .01 \\
\hline \multicolumn{3}{|l|}{ Inconvenience caused by warts } \\
\hline Yes & $38(16-90)$ & $<.001$ \\
\hline Type of inconvenience ${ }^{d}$ & $11(5.6-23)$ & $<.001$ \\
\hline Pain & $21(4.8-91)$ & $<.001$ \\
\hline Irritation & $27(6.3-118)$ & $<.001$ \\
\hline Unsightly appearance & $20(6.7-57)$ & $<.001$ \\
\hline Opinion of others & $16(2.0-126)$ & .01 \\
\hline \multicolumn{3}{|l|}{ OR = odds ratio. } \\
\hline \multicolumn{3}{|c|}{$\begin{array}{l}\text { a Generated by univariate logistic regression model. } \\
\text { b Proxy for persistent warts. } \\
\text { ' OR per unit on a scale from } 1 \text { (little inconvenience) to } 4 \text { (considerable } \\
\text { inconvenience). } \\
{ }^{d} \text { Reported retrospectively by parents. }\end{array}$} \\
\hline
\end{tabular}


or wart growth, resolution rates after 1 year were objectively established by physical inspection of hands and feet. Warts on other parts of the body were potentially missed, but they account for less than $4 \%$ of all warts. ${ }^{17}$

We collected information on initiated treatments because treatment effects might play a role in the observed resolution rates. In agreement with a study among Australian schoolchildren, ${ }^{2}$ about one-third of children with warts had sought treatment, for which a wide range of OTC and family physician treatments were available. The remaining two-thirds decided to refrain from treatment or were simply not aware of the presence of warts. Parental questionnaires completed before the baseline examination showed that approximately one-half of all children had warts that had not been noticed earlier by their parents. ${ }^{3}$ The present study shows that on a yearly basis, family practice encounters only $20 \%$ of all children with warts. These children have larger and more inconvenient warts with poorer resolution rates than children who did not seek treatment. Further interpretation of these findings is limited, however, because selection and recall bias are probably involved. We had no information on the duration of warts at baseline; moreover, retrospectively, the parents of children with persistent warts may more easily have recalled treatments and inconvenience than the parents of children with resolved warts. In a recent randomized controlled trial in a family practice population, the resolution rate in children after a wait-andsee policy of 3 months was 29\% (95\% CI, 17\%-45\%). ${ }^{10}$

\section{Implications}

Warts are a persistent problem for some children, regardless of treatments. Age and skin type influence the odds of resolution. Our findings will be useful in the process of shared decision making with parents and children. Patients and family physicians should weigh the benign natural course, the adverse effects of treatments, and the costs on the one hand, and the effectiveness of treatments and the risk of spreading untreated warts on the other. Future research needs to more precisely establish the time to resolution of warts and identify subgroups of patients with relatively low natural resolution rates and high treatment response rates.

To read or post commentaries in response to this article, see it online at http://www.annfammed.org/content/11/5/437.

Key words: cutaneous warts; schoolchildren; natural course; primary care

Submitted July 20, 2012; submitted, revised, November 27, 2012; accepted December 27, 2012.

Funding support: This work was supported by the Netherlands Organisation of Health Research and Development, Fund Common Diseases.
Disclaimer: The Netherlands Organisation of Health Research and Development, Fund Common Diseases did not have any influence on the study design; the collection, analysis, or interpretation of data; the writing of the manuscript; or the decision to submit the manuscript for publication.

Acknowledgments: We thank all the primary schoolchildren and their parents for their enthusiastic participation. We also thank Femke van Haalen for the collection of baseline data.

\section{References}

1. Androphy EJ, Lowy DR. Warts. In: Wolff K, Goldsmith LA, Katz SI, Gilchrest BA, Paller AS, Leffell DJ, eds. Fitzpatrick's Dermatology in General Medicine. 7th ed. New York, NY: McGraw-Hill; 2008: 1914-1923.

2. Kilkenny M, Merlin K, Young R, Marks R. The prevalence of common skin conditions in Australian school students: 1. Common, plane and plantar viral warts. Br J Dermatol. 1998;138(5):840-845.

3. van Haalen FM, Bruggink SC, Gussekloo J, Assendelft WJ, Eekhof JA. Warts in primary schoolchildren: prevalence and relation with environmental factors. Br J Dermatol. 2009;161(1):148-152.

4. Westert GP, Schellevis FG, de Bakker DH, Groenewegen PP, Bensing JM, van der Zee J. Monitoring health inequalities through general practice: the Second Dutch National Survey of General Practice. Eur J Public Health. 2005;15(1):59-65.

5. Schofield J, Grindlay D, Williams HC. Skin Conditions in the UK: A Health Care Needs Assessment. Nottingham, United Kingdom: Centre of Evidence Based Dermatology, University of Nottingham; 2009.

6. Bruggink SC, Waagmeester SC, Gussekloo J, Assendelft WJ, Eekhof JA. Current choices in the treatment of cutaneous warts: a survey among Dutch GP. Fam Pract. 2010;27(5):549-553.

7. Thomas KS, Keogh-Brown MR, Chalmers JR, et al. Effectiveness and cost-effectiveness of salicylic acid and cryotherapy for cutaneous warts. An economic decision model. Health Technol Assess. 2006; 10(25): ix-87.

8. Gibbs S, Harvey I. Topical treatments for cutaneous warts. Cochrane Database Syst Rev. 2006;3(3):CD001781.

9. Cockayne S, Curran M, Denby G, et al; EVerT team. EVerT: cryotherapy versus salicylic acid for the treatment of verrucae-a randomised controlled trial. Health Technol Assess. 2011;15(32):1-170.

10. Bruggink SC, Gussekloo J, Berger MY, et al. Cryotherapy with liquid nitrogen versus topical salicylic acid application for cutaneous warts in primary care: randomized controlled trial. CMAJ. 2010;182 (15):1624-1630.

11. British Association of Dermatologists. Patient information leaflet on plantar warts [Web site, updated 2012]. http://www.bad.org.uk/ site/859/Default.aspx. Accessed Aug 9, 2013.

12. Massing AM, Epstein WL. Natural history of warts. A two-year study. Arch Dermatol. 1963;87:306-310.

13. Van Der Werf E. Een onderzoek naar het vóórkomen en het verloop van wratten bij schoolkinderen. [Studies on the incidence and course of warts in school children.] Ned Tijdschr Geneeskd. 1959;103(23):1204-1208.

14. Williams HC, Pottier A, Strachan D. The descriptive epidemiology of warts in British schoolchildren. Br J Dermatol. 1993;128(5):504-511.

15. Fitzpatrick TB. The validity and practicality of sun-reactive skin types I through VI. Arch Dermatol. 1988;124(6):869-871.

16. Burkhart CG. The endogenous, exogenous, and latent infections with human papillomavirus. Int J Dermatol. 2004;43(7):548-549.

17. Larsson PA, Lidén S. Prevalence of skin diseases among adolescents 12-16 years of age. Acta Derm Venereol. 1980;60(5):415-423. 